\title{
POLÍTICAS EDUCACIONAIS ORIENTADAS À INOVAÇÃO
}

\author{
EDUCATIONAL POLICIES FOR INNOVATION
}

\author{
Karina Domingues Bressan VIDAL ${ }^{1}$ \\ Ivan Rocha NETO ${ }^{2}$
}

RESUMO: Considerando que as tecnologias digitais influenciaram não apenas o ambiente escolar mas os hábitos de uma geração, este artigo explora os desafios dos formuladores de políticas educacionais voltadas para o desenvolvimento do indivíduo para o século XXI. Foi realizada uma pesquisa bibliográfica nas principais estratégias educacionais implementadas por países que obtiveram alta classificação no Programa Internacional de Avaliação de Estudantes em 2012 e nas estratégias brasileiras. A pesquisa bibliográfica apontou que é necessário não apenas investir em infraestrutura e formação de professores, mas também em uma reforma curricular flexível, voltada para a realidade local; realizar revisão da proposta pedagógica, valorizando a construção do conhecimento ao invés da memorização; alterar o processo de avaliação, aplicando a auto-avaliação e avaliação por pares, ao invés dos testes tradicionais; investir no desenvolvimento profissional dos professores; reestruturar a escola; e avaliar constantemente os resultados por meio de indicadores.

Palavras chave: Educação. Tecnologias digitais. Políticas públicas.

ABSTRACT: Whereas digital technologies influenced not only the school but the habits of a generation, this article explores the challenges of educational policies focused on the development of the individual for the 21 st century. A literature search was performed in the main educational strategies implemented by countries that have achieved high rank in the International Student Assessment Program in 2012 and in the Brazil's strategies. The research pointed out that it is necessary not only to invest in infrastructure and training of teachers, but also in a flexible curricular reform geared to the local reality; perform review of pedagogical proposal, valuing the knowledge construction instead of memorization; change the evaluation process, applying the selfevaluation and peer review, instead of traditional tests; investing in the professional development of teachers; restructure the school; and assess constantly the results through indicators.

KEYWORDS: Education. Digital technologies. Public policies.

1 Analista de Ciência e Tecnologia no Ministério da Ciência, Tecnologia e Inovação. Doutoranda pela Universidade Federal do Rio Grande do Sul. E-mail: karinabvidal@hotmail.com

${ }^{2} \mathrm{PhD}$ em Eletrônica pela Universidade de Kent at Canterbury, UK. Universidade Federal do Rio Grande do Sul. E-mail: neto-ivan@ hotmail.com 


\section{Introdução}

Há consenso entre os formuladores de políticas de que o desenvolvimento de um País está condicionado à qualidade da sua educação. A educação desenvolve as habilidades produtivas dos trabalhadores e a capacidade para absorver novas ideias. Essas habilidades aumentam a produtividade da economia e geram inovação

Melhorar a educação e desenvolver competências que estimulem o estudante a procurar pelo desconhecido, que seja criativo, conectado e se torne mais autônomo, tem sido o foco central para as estratégias de desenvolvimento de muitos países.

Com a introdução das Tecnologias de Comunicação e Informação (TIC) no sistema educacional, um fenômeno relativamente novo e crescente, os formuladores de políticas públicas passaram a ter mais um desafio: identificar como as TIC podem ser melhor utilizadas para apoiar a mudança da educação e como pode a sua aplicação na educação sustentar o desenvolvimento econômico e a transformação social no século XXI.

Nos últimos anos, em todo mundo, tem-se visto uma constante incorporação das tecnologias digitais na sala de aula, com uso de quadros interativos - lousas digitais, ambientes virtuais de aprendizagem coletiva, tablets, celulares, jogos de computador educativos e crescente dependência de aplicações de internet, dentro e fora da sala de aula. Esse crescimento tem sido tão exponencial que as TIC são consideradas por autores como uma forma de promover a mudança educacional, melhorar as competências dos estudantes e prepará-los para a economia global e da sociedade da informação (KOZMA, 2005). Para Ezell e Andes (2010) as TIC podem ser consideradas os principais motores do desenvolvimento econômico e da mudança social.

Segundo Kozma (2008), as estratégicas podem fornecer uma sustentação, um conjunto de metas e uma visão de como poderia afetar os sistemas educativos e como os estudantes, pais, professores e população podem se beneficiar com o seu uso na escola. Essas podem motivar a mudança e coordenar esforços dispares para avançar nos objetivos educacionais nacionais mais abrangentes. E as políticas operacionais devem acompanhar a instalação de programas e fornecer recursos para essas mudanças.

$\mathrm{O}$ autor complementa que sem uma estratégia para guiar o uso da tecnologia na educação de um país, as políticas de TIC são apenas operacionais, ou seja, se resumem em compras de equipamentos ou a formação de professores, sem proporcionar um propósito educacional. 
Nas próximas seções são investigadas as políticas educacionais adotadas em alguns países e no Brasil.

\section{Politicas educacionais}

Kozma (2008) identifica quatro alternativas estratégicas, as que: apoiam o crescimento econômico; promovem o desenvolvimento social. Quanto ao impacto das TIC na educação: se propõem avançar fazendo uma reforma educacional; e, se propõem a fortalecer a gestão da educação.

Para o autor, as políticas nacionais de TIC têm o maior impacto se devidamente associadas umas com as outras e com seus diferentes níveis de desempenho. Este alinhamento é composto por três níveis: o nível estratégico para o operacional, o horizontal e o vertical. O primeiro refere-se à coerência com as políticas operacionais e estratégicas para assegurar que os programas de TIC e projetos estão ajustados diretamente com a visão e com os objetivos da nação. $\mathrm{O}$ alinhamento horizontal assegura que as políticas de TIC estejam coerentes com outras políticas dentro do sistema de ensino; enquanto o vertical refere-se à coordenação das visões e ações para baixo e para dentro do sistema de ensino.

Os componentes das políticas operacionais são (KOZMA, 2008):

- O desenvolvimento de infraestrutura, quanto a hardware, software, intranet e conectividade, bem como recursos relacionados com televisão e rádio.

- A formação de professores, especialmente para políticas estratégicas que visam reformar a educação. Podem incluir desde a formação básica em e-mail, Internet, software e usos administrativos, ao conhecimento mais avançado sobre como integrar as TIC no currículo e na prática da sala de aula todos os dias ou redes e trabalho colaborativo.

- O suporte técnico, que é de grande importância não só em fases iniciais, mas como a manutenção de hardware e tecnologias que evoluem.

- As mudanças curriculares e pedagógicas, especialmente para as políticas estratégicas cujo objetivo é promover a reforma da educação.

- O desenvolvimento de conteúdo. 
O Programa Internacional de Avaliação de Estudantes (PISA) 2012, publicou em seu último relatório (OCDE, 2014) um ranking entre os 44 países participantes referente a qualidade da educação. Os primeiros lugares ficaram com Cingapura - 562 pontos; Coreia do Sul - 561; Japão - 552; China/Macau - 540; China/Hong Kong - 540; China/Xangai - 536; China/Taipé - 534; Canadá - 526; Austrália - 523; Finlândia 523; Reino Unido - 517; Estônia - 515; França - 511; Holanda - 511; Itália - 510; República Tcheca - 509; Alemanha - 509.

O Brasil ficou em $38^{\circ}$ lugar, com 428 pontos. O resultado do PISA mostrou ainda que só $2 \%$ dos alunos brasileiros conseguiram resolver problemas de matemática mais complexos. Entre os estrangeiros, esse número chegou a $11 \%$. O programa tem como objetivo produzir indicadores que contribuam para a avaliação da qualidade da educação nos países participantes da OCDE, de modo a subsidiar políticas de melhoria do ensino básico, e verificar até que ponto as escolas de cada país participante estão preparando seus jovens para exercer o papel de cidadãos na sociedade contemporânea.

Nesse sentido, investigaremos alguns países de obtiveram os primerios resultados no ranking.

Cingapura implantou uma coordenação centralizada entre Ministérios, subordinados a Política Nacional de Educação, a qual tinha como interesses econômico o desenvolvimento de clusters industriais (KOZMA, 2005). No final de 1990, o governo reconheceu que precisava aumentar sua pesquisa, desenvolvimento e inovação tecnológica, melhorar a criatividade de sua força de trabalho e promover o empreendedorismo local e a participação generalizada na economia. Então o governo criou impostos para educação, cujos fundos foram colocados em requalificação e poderiam ser devolvidos para empresas que participaram em programas de formação. Em 1997, Cingapura iniciou um plano de 5 anos de TIC, designado "Plano Diretor de Informática na Educação", para incorporar tecnologia no sistema escolar, cujo foco principal era na instalação de computadores e acesso à Internet de banda larga nas escolas e salas de aula e treinamento de professores sobre o uso de computadores. Em 2002, o Ministério lançou o seu Plano Master 2, em coordenação com "Escolas de pensamento: Learning Nation". O novo plano diretor adotou uma abordagem sistêmica, em que todos os principais componentes do sistema de TIC, currículo, avaliação, formação, desenvolvimento profissional e cultural foram integrados. Mudanças em uma área tinha correspondência a mudanças em outras áreas dentro do Ministério da Educação. 
A Coréia do Sul em 30 anos se transformou de um país pobre e carente de recursos naturais para uma nação industrializada devido a fatores econômicos que incluem a industrialização pesada, a estratégia de comércio voltada para exportação e a forte e bem-sucedida política educacional com absorção de novas tecnologias (centralizada no governo federal desde o primeiro ano escolar). O País possui $80 \%$ com conexões em banda larga, até mesmo na área rural. Quanto a inovação, cientistas sulcoreanos desenvolveram uma tecnologia tridimensional 3D para livros animados que leva os personagens a literalmente saltarem das páginas; essa tecnologia poderá ser usada em qualquer livro (SOUZA, JESUS, 2001).

O Japão, segundo Furtado (2014), apesar se ser um país altamente tecnológico, o uso de ferramentas digitais em sala de aula e em cursos on-line encontram barreiras devido ao modelo tradicional de ensino-aprendizagem. Essa realidade esta mudando, pois o País entende a necessidade de transformar o estudante em um ser autônomo, nesse sentido alguns institutos já estão optando pelo ensino híbrido.

A China vem modernizando seu sistema educacional para garantir lideranca econômica, para isso tem transformado sua educação mais aberta, o inglês é introduzido desde cedo e os estudantes estão estudando no exterior. Possui o maior número de internautas do mundo, apesar do controle de censura (WASSERMANN, 2009).

A Finlândia implementou uma política educacional descentralizada e de base ampla, ligando o sistema educativo para as comunidades cívicas e empresariais. As decisões sobre currículo e instrução são elaboradas por escolas e professores locais (KOZMA, 2005). O papel do governo na Finlândia é fomentar a inovação, a criação e compartilhamento de conhecimento. Implantou políticas e programas para apoiar esta visão por meio do desenvolvimento de habilidades de construção de conhecimento entre professores e alunos e através do uso de abordagens focadas no aluno e na colaboração para a aprendizagem. O compromisso inclui a escolaridade de alta qualidade a partir do jardim de infância até a universidade e cuidados de saúde universal. Para chegar nesse estágio, a Finlândia, vendeu estatais, investiu em Institutos e Incubadoras. Cada escola escreve o seu próprio currículo com base em orientações muito gerais do Conselho Nacional de Educação e desenvolve através de discussões entre professores e pais. São dadas autoridades as escolas e aos professores a para selecionar materiais de ensino que correspondem ao currículo. As empresas trabalham em estreita colaboração com as escolas. Quase um terço dos alunos do ensino secundário estão matriculados no ensino profissional. O ensino profissional é conduzido em colaboração com as empresas locais 
através de estágios e on-the-job training e com líderes empresariais que participam no processo de decisão da escola. A finalidade do ensino superior finlandês é apoiar a investigação e desenvolvimento.

Nos Países Europeus a integração das TIC na educação é o desenvolvimento de habilidades para que os cidadãos possam ter condições de enfrentar um mercado de trabalho cada vez mais exigente. A maioria dos países europeus superaram algumas etapas da política operacional. Reino Unido, Suíça, Suécia, Holanda, Itália, Noruega, Bélgica, Áustria, Espanha, Chipre, Hungria, República Checa, Turquia e Eslovénia têm uma estratégia global, focada em prover a infraestrutura necessária para alcançar a plena integração da tecnologia na educação. $\mathrm{O}$ apoio do fornecimento de equipamento e infraestrutura ocorre em várias formas( (VACCHIERI, 2013):

- As escolas devem criar um projeto educativo e submetê-lo ao Ministério da Educação relevante para uma subvenção, a fim de receber infraestrutura e serviços de TIC. Tal é o caso da Hungria, República Checa, Portugal e Alemanha. No caso da Estónia e Itália, para as subvenções, os centros devem demonstrar sua experiência no uso pedagógico das TIC.

- Programas de âmbito nacional que começaram com projetos-piloto, somente em uma região ou em um pequeno grupo de centros para estudar a implementação e o impacto dos netbooks no ensino e aprendizagem; e numa segunda fase, os resultados são aplicados ao sistema nacional, como a Escola 2.0 na Espanha e Home Access no Reino Unido.

- Algumas iniciativas são baseadas no fornecimento de subsídios para as famílias de baixa renda ou famílias em geral, como no caso do Reino Unido, Alemanha, Áustria e Espanha (Catalunha).

- Em outros projetos, o Ministério da Educação, em cooperação com empresas privadas, prevê incentivos para estudantes ou famílias que podem adquirir netbooks ou laptops a preços baixos, muitas vezes com conectividade de banda larga incluído. Às vezes os centros podem comprar lousas e outros equipamentos como um incentivo para os seus programas. Esta situação acontece na França, Itália, Malta, Polónia, Portugal e Israel. 
Em relação aos Estados Unidos em 1983 a Nation at Risk recomendou a inclusão da disciplina "Ciência da Computação" (Inglês, matemática, ciências, estudos sociais, ciência da computação) como um dos requisitos principais de conclusão do ensino médio americano (CULP; HONEY; MANDINACH, 2005). Desde então, as escolas americanas fizeram melhorias dramáticas em sua capacidade tecnológica, impulsionado em grande parte pelos investimentos públicos e privados. Em 2001, o Child Left Behind Act (NCLB) incluiu uma recomendação para que no oitavo ano todos os alunos devessem ser tecnologicamente alfabetizados, e tecnologia deveria ser considerada como uma importante fonte de apoio para o ensino e a aprendizagem em todo o currículo. Em 2016, segundo Smith (2016), a Ciência da Computação para todos é o novo foco do Presidente Obama para capacitar todos os estudantes americanos do jardim de infância até o ensino médio para aprender Ciência da Computação e ser equipado com as habilidades de pensamento computacional que necessitam para serem criadores na economia digital, não apenas os consumidores, e ser ativo cidadãos em um mundo orientado à tecnologia. Segundo o autor, a economia está mudando rapidamente, e tanto os educadores como os líderes empresariais estão cada vez mais reconhecendo a habilidade em Ciência da Computação como necessária para as oportunidades econômicas e a mobilidade social.

Os Países latino-americanos têm seguido como estratégica principal o desenvolvimento social, sobretudo relacionada com a inclusão social e a redução na lacuna digital e, em alguns casos, não em todos, também para a melhoria da qualidade educacional.

O Brasil segundo o Plano Nacional de Educação tem como meta fomentar o desenvolvimento de tecnologias educacionais e de práticas pedagógicas inovadoras que assegurem a alfabetização e favoreçam a melhoria do fluxo escolar e a aprendizagem dos estudantes consideradas as diversas abordagens metodológicas e sua efetividade; e universalizar o acesso à rede mundial de computadores em banda larga de alta velocidade e aumentar a relação computador/aluno nas escolas da rede pública de educação básica, promovendo a utilização pedagógica das tecnologias da informação e da comunicação; e promover a reforma curricular dos cursos de licenciatura e estimular a renovação pedagógica, de forma a assegurar o foco no aprendizado do aluno, dividindo a carga horária em formação geral, formação na área do saber e didática específica e incorporando as modernas tecnologias de informação e comunicação, em articulação com a base nacional comum dos currículos da educação básica. 
Para atingir a meta, o governo, por meio do Ministério da Educação, criou em 1977 o PROINFO inicialmente denominado de Programa Nacional de Informática na Educação com a finalidade de promover o uso da tecnologia como ferramenta de enriquecimento pedagógico no ensino público fundamental e médio. A partir de 2007, o PROINFO passou a ser Programa Nacional de Tecnologia Educacional, tendo como principal objetivo promover o uso pedagógico das tecnologias de informação e comunicação nas redes públicas de educação básica. O funcionamento do PROINFO se dá de forma descentralizada, existindo em cada unidade da Federação uma Coordenação Estadual, e os Núcleos de Tecnologia Educacional, dotados de infraestrutura de informática e comunicação que reúnem educadores e especialistas em tecnologia de hardware e software.

Os projetos e programas contidos no PROINFO são: Projeto Um Computador por Aluno; Programa um computador por aluno; Programa Banda Larga nas Escolas (PBLE); e o mais recente: tablets educacionais.

\section{Sugestão para a reforma educacional}

Segundo Kozma (2008), o objetivo de uma reforma educacional é desenvolver capacidades nos estudantes, escolas, professores, escolas e comunidades para criar, compartilhar e usar novos conhecimentos, de tal forma que a criação do conhecimento individual e organizacional, aprendizagem, e melhoria tornam-se atividades contínuas e auto-sustentadas. Estas capacidades apoiam uma mudança qualitativa na economia. A capacidade dos trabalhadores individualmente e para a sociedade em conjunto para pensar de forma criativa e inovadora e para criar continuamente, compartilhar e utilizar novos conhecimentos leva não só a melhores maneiras de fazer as coisas antigas, mas também novas maneiras de fazer as coisas inteiramente novas, resultando em transformação econômica e no crescimento sustentado.

Para isso, o autor examina que implicações dessas abordagens na reforma educacional, como: mudanças no currículo, na proposta pedagógica, nas avaliações, no desempenho dos professores, e na estrutura da escola.

Os currículos têm tradicionalmente focado no escopo e na sequiência de conteúdos que devem ser abrangidos por um programa educacional. Estes são codificados como fatos, conceitos, princípios e procedimentos relativos à matemática, 
biologia, história, língua, e assim por diante. Muitas vezes compreender e trabalhar nas idéias dos alunos é sacrificado devido a quantidade de conteúdos que devem ser cumpridos. Muitas vezes as escolas enfatizam a memorização de fatos e procedimentos específicos fora do contexto de seu uso no mundo real e para além das experiências que os alunos podem trazer com eles para a sala de aula e as necessidades das comunidades a que eles retornam. É necessário revisar o currículo para preparar melhor os alunos para o mundo do trabalho. Os alunos aprendem melhor quando as metas curriculares são construídas dentro de seus próprios interesses e experiências cotidianas e eles estão melhor preparados para o mundo fora da escola quando essas metas estão ligadas às condições e necessidades da comunidade. Isto implica que as escolas e até mesmo os professores devam ter um certo grau de flexibilidade no quadro curricular para ajustar objetivos instrucionais para os interesses de grupos particulares ou alunos individuais e aos objetivos da comunidade $\mathrm{e}$ as necessidades das empresas locais. Como consequência, as metas curriculares relacionadas com a matemática, ciências, social estudos e literatura pode ser um pouco diferente para os estudantes rurais do que alunos de áreas urbanas e para os de diferentes origens culturais, com base nas necessidades sociais e econômicas de suas comunidades locais.

No método de ensino e aprendizagem tradicional, os professores são as principais fontes de conhecimento, que transmitem aos estudantes os quais recebem passivamente e registraram esse conhecimento na memória. A reforma pedagógica propõe que os estudantes estejam ativamente empenhados em aplicar seus novos conhecimentos para a solução de tarefas complexas. Professores devem apoiar a aprendizagem do aluno na individualização, olhando para as necessidades dos alunos, abordando equívocos que possam ter, e fornecendo o tempo que os alunos precisam aprender. No entanto, mover o sistema de educação para além memorização do conteúdo para a criação do conhecimento envolve uma participação mais profunda dos estudantes na sua própria aprendizagem. Aprender a aprender é tanto uma meta como uma prática de sala de aula central.

Enquanto avaliações tradicionais dependem de múltipla escolha ou preencher as respostas em lacunas que favoreçam os níveis mais baixos de conhecimento; avaliações e projetos de desempenho proporcionam aos estudantes avaliações que examinam níveis mais elevados de conhecimento e são mais parecidos com os tipos de avaliações que encontram no mundo real. Avaliações de desempenho são particularmente úteis na exibição de conhecimentos e seus processos cognitivos e sociais de ambos os estudantes 
e esta informação pode ajudar os professores no planejamento das intervenções subseqüentes. Auto-avaliação e avaliação por pares pode ser particularmente importante no apoio ao desenvolvimento de competências metacognitivas e melhoria contínua. Com a orientação de professores, os estudantes usam auto-avaliações e avaliação por pares para desenvolver habilidades para monitorar seu próprio progresso. Da mesma forma, quando os professores compartilham suas metas e planos de ensino, observar a prática do outro, e apoiar os esforços mútuos de desenvolvimento profissional, criam uma expectativa de um ensino de qualidade e torna-se um valor fundamental da escola. Usado desta forma, as reformas de avaliação melhoraram o desempenho de professores e aprendizagem dos alunos.

Quanto ao desenvolvimento profissional de professores que precisam além da compreensão do conteúdo o conhecimento pedagógico sobre como os estudantes aprendem o conteúdo e como ele pode ser melhor ensinado. A transformação da educação exige que os professores se envolvam na aprendizagem auto-sustentada, na criação do conhecimento, na inovação e no compartilhamento do conhecimento. A este respeito, os pesquisadores defendem uma abordagem para desenvolvimento profissional de professores que constrói uma comunidade de prática focada na melhoria contínua. Com esta abordagem, os professores trabalham em conjunto, dentro de áreas e em todas as escolas, para identificar problemas de prática, de forma colaborativa gerado e experimentar soluções, partilhar recursos e melhores práticas, e construir um corpo de conhecimentos profissionais que influencia sala de aula.

Quanto a organização escolar, as escolas tradicionais são estruturas hierárquicas com a prática de sala de aula dos professores rigidamente controladas por inspetores curriculares e diretores. Nas escolas reestruturados para a compreensão, os estudantes trabalham juntos em projetos estendidos e engajados e os professores trabalham com os estudantes e os seus colegas sobre a concepção de um ambiente que apoia a aprendizagem. Estas práticas são facilitadas por mudanças estruturais na escola, como para permitir o agrupamento estudante flexível ou alterar o calendário escolar para permitir mais tempo para projetos de estudantes e mais tempo para planejamento dos professores e colaboração.

Considerando estas abordagens, Kozma (2005), apontou quatro tipos de aplicações para as TIC na educação: 
Com a finalidade de serem utilizadas para melhorar a entrega e o acesso à educação: A tecnologia pode ser usada para melhorar a forma que os métodos de instrução são entregues, tornando a instrução mais eficiente, menos dispendiosa e mais acessível. Por exemplo, elas podem ter importantes contribuições nas zonas rurais e para os países menos desenvolvidos, onde o acesso à educação é muitas vezes limitado. Os alunos podem ter acesso a uma vasta gama de recursos multimídia, relacionados a eventos atuais, ciência, estudos sociais e cultura. Os professores podem ter acesso a materiais curriculares e outros recursos.

$\checkmark$ Com foco na aprendizagem: ao aprender competëncias em TIC, os estudantes tormam-se mais bem preparados para o trabalho no qual envolve cada vez mais a utilização das tecnologias.

$\checkmark$ Com base no apoio à compreensão do aluno: As TIC podem ser utilizadas para melhorar a compreensão dos estudantes para resolução de problemas complexos e reais que atravessam as fronteiras disciplinares, aumentar a qualidade da educação e, consequentemente, aumentar o impacto da educação sobre a economia.

$\checkmark$ No apoio a criação de conhecimento, tecnologia, inovação tecnológica e compartilhamento do conhecimento podem contribuir para a transformação do sistema de ensino e para o crescimento econômico sustentado e para o desenvolvimento social. A tecnologia pode ser usada, juntamente com reformas pedagógicas, curricular e de avaliação para apoiar o processo de criação de conhecimento em que os alunos e professores podem definir seus próprios objetivos, planejar suas atividades de aprendizagem, construir sobre as idéias uns dos outros e assim criar novos conhecimentos.

\section{Conclusão}


"O mundo em que vivemos é cada vez mais sofisticado, multifacetado e diversificado. As pessoas precisam de habilidades de aprendizagem de alto nível para agir, responder, aprender e adaptar-se a circunstâncias em constante mudança. Enquanto o mundo cresce cada vez mais complexo, o sucesso e a prosperidade será ligada à capacidade das pessoas de pensar, agir, adaptar-se e comunicar-se de forma criativa" (CULP; HONEY; MANDINACH, 2003).

Esse estudo apresentou um resumo das Políticas Educacionais adotadas por países com com maior desempenho no sistema escolar, segundo a OCDE, e as adotaas na América do Sul. Devido a incorporação das tecnologias digitais no cotidiano das pessoas, que por sua vez tem causado uma constante mudança em todos os setores da economia, esse trabalho enfatizou a contribuição das TIC para uma reforma educacional capaz de preparar um indivíduo para os novos desafios desse século.

Como o mundo esta mudando rápido, o que é novo hoje pode estar obsoleto amanhã, criar Políticas e Programas educacionais capazes de preparar um indivíduo a aprender a aprender, tornar-se autônomo e capaz de criar, passou a ser considerado prioridade em muitos países.

Entretanto, observamos que não basta equipar escolas com computadores, há necessidade de implemantar uma política forte, integrada e coordenada em torno de metas e visões claras, como foi o caso de Cingapura e Finlândia.

Há necessidade de uma reforma educacional, que prepare os indivíduos para o mercado de trabalho, assim como enfatiza os estudos nos Paises Europeus. Essa reforma educacional envolve flexibilidade no currículo, na proposta pedagógica, nos métodos de avaliação, na estrutura organizacional e principamente na profissionalização do professor, como um agente ativo e inovador.

É claro que nos países em desenvolvimento, onde os recursos são escassos, os formuladores de políticas devem priorizar investimentos, implantar politicas de inclusão social para diminuir as diferenças sociais. Entretanto, parcerias com o setor privado pode ser uma boa alternativa para apoiar uma mudança sustentada.

Outro fator imprescindível é a criação de indicadores mensuráveis, que possam monitorar e avaliar os resultados, pois investimentos públicos exigem um retorno significativo em termos de educação, social e benefícios econômicos. Planos de desenvolvimento nacional deve especificar uma trajetória clara de resultados esperados. Medidas, tanto do processo de implementação e do resultado devem ser utilizados para 
monitorar continuamente o progresso dos programas em direção a objetivos e fornecer informações aos responsáveis políticos que podem ser utilizados para refinar políticas e programas e ajustar trajetórias. Desta forma, as políticas e programas iniciais podem ser moldadas para assegurar coordenação permanente e promover mudanças fundamentais na educação, na sociedade e na economia.

\section{Referências}

CULP, Katie McMillan; HONEY, Margaret; MANDINACH, Ellen. A retrospective on twenty years of education technology policy. Journal of Educational Computing Research, v. 32, n. 3, p. 279-307, 2005.

EZELL, Stephen; ANDES, Scott. ICT R\&D policies: an international perspective. Internet Computing, IEEE. v. 14, n. 4, p. 76-80, 2010. Disponível em: <http://www.itif.org/files/ICTRandD.pdf>. Acesso em: 26 jul. 2015.

FURTADO, Paula. Ensino híbrido incentiva autoaprendizagem no Japão. Porvir. Disponível em: < http://porvir.org/ensino-hibrido-incentiva-autoaprendizagem-japao/>. Acesso em: 24 abril. 2016.

KOZMA, Robert B. National Policies that Connect ICT-Based Education Reform to Economic and Social Development. Human Technology, v 1 (2), p. 117-156. 2005. Disponível em: <http://www.humantechnology.jyu.fi>. Acesso em: 24 abril. 2016.

KOZMA, Robert B. Comparative Analysis of Policies for ICT in Education Center for Technology in Learning, en SRI International. J. Voogt y G. Knezek (eds.):

International

handbook of information technology in primary and secondary education. Berlín:

Springer

Science. Traducción propia. 2008. Disponível em:

<http://robertkozma.com/?q=node/5>. Acesso em: 24 abril. 2016.

SMITH Megan. Computer Science For All . The WHITE HOUSE. Disponível em: <https://www.whitehouse.gov/blog/2016/01/30/computer-science-all>. Acesso em: 24 abril. 2016.

VACCHIERI, A. Estado del arte sobre la gestión de las políticas de integración de computadoras y dispositivos móviles en los sistemas educativos. UNICEF Argentina, v. 10. 2013.

YOON, Taek Dong; SOUZA, Nali de Jesus. Uma análise empírica sobre os fatores do desenvolvimento econômico da Coréia do Sul: 1961-1990. Estudos econômicos, 2001.

WASSERMANN Rogerio. China moderniza educação para garantir liderança econômica. BBC Brasil. Disponível em: 
<http://www.bbc.com/portuguese/noticias/2009/04/090402_china_modernizacao.shtml $>$. Acesso em: 24 abril. 2016.

\section{Como referenciar este artigo}

VIDAL, Karina Domingues Bressan.; NETO, Ivan Rocha. Políticas educacionais orientadas à inovação. Revista on line de Política e Gestão Educacional, Araraquara, v.20, n.2, $\quad$ p. 257-270, 2016. Disponível em: <http://dx.doi.org/10.22633/rpge.v20.n2.9462>. ISSN: 1519-9029.

Submetido em: jun/2016

Aprovado em: dez/2016 